\title{
Pharmacokinetics of Dietary Isoflavones
}

\section{Sabarinath Chandrasekharan* and Annie Aglin}

Department of Biotechnology, PSG College of Technology, India

\begin{abstract}
Dietary isoflavones are reported to have significant influences on human health. The beneficial effects reported include reduced risk of cancers, decreased menopausal symptoms, reduced osteoporosis etc. Most of these benefits have been deduced from epidemiological studies involving soy bean as the source of dietary isoflavones, since soy bean is an important food crop in several parts of the world. Over the last 30 years, considerable progress has been made in understanding the fate of dietary isoflavones in humans. Now we understand that the pharmacokinetics of dietary isoflavones is a complex phenomenon and involving multifaceted biological processes. The role of gut micro flora in deciding the bioavailability of isoflavones is quite significant. This review examines various pharmacokinetic aspects of dietary isoflavones and factors influencing the systemic bioavailability of isoflavones. This review also attempts to identify important factors which may contribute to the inter-person differences in the effects of isoflavones.
\end{abstract}

Keywords: Dietary isoflavones; Genistein; Equol; Gut microflora; Pharmacokinetics

\section{Introduction}

Isoflavones are polyphenolic compounds found in many plant families, but especially in some members of the Fabaceae family. It is reported in several agriculturally important legumes such as soy, peanut, green peas, chick peas and alfalfa $[1,2]$. Soy (Glycine max) beans are exceptionally rich in isoflavones, with an average content of 1-2 mg/gram [3] and constitute the major source for dietary isoflavones. The main isoflavones in soy beans, present in glycosylated form, are genistin, daidzin and glycetin $[3,4]$. The glycosylation is on the $7^{\text {th }}$ position of Ring $\mathbf{A}$ in the isoflavone ring (Table 1). The aglycone form of these isoflavones known as genistein, daidzein and glycitein respectively, are biologically active $[1,5]$. Biochanin $\mathrm{A}$ and formononetin are other isoflavones present in legumes, which can be converted by 4'-O-demethylation to the more potent genistein and daidzein [6]. Red clover (Trifolium pretense) contains Biochanin A and formononetin, in addition to other isoflavones. Kudzu (Pueraria lobata), root used as a condiment in East Asian cuisine and in hangover remedies, contains Puerarin (daidzein 8 -C-glucoside) in significant amount $[1,7]$.

Soy products are consumed in a variety of forms including whole beans, flour, soy protein isolates, textured soy protein, etc. $[1,8]$. Fermented soy products like miso, tempeh and soy sauce are used regularly as part of East Asian cuisine [1,3]. Although the starting raw material is soy bean, the isoflavone content in these foods varies according to the preprocessing and cooking procedure [1,9]; for example, microbial fermentation converts the glycosylated isoflavones to aglycones and prolonged fermentation leads to complete loss of isoflavones [1]. An elaborate database of isoflavone content in unprocessed and processed soy products is available from United States Department of Agriculture (http://www.nal.usda.gov/fnic/foodcomp/ Data/isoflav/isoflav.html).

Several epidemiological investigations on health benefits of isoflavone-rich diets, especially soy based food regimes, showed lower incidences of colonic cancer [10], prostate cancer [11], coronary disease $[12]$, breast cancer [12,13] and osteoporosis [14]. As the benefits of dietary isoflavones became evident, tremendous interest was created in investigating the pharmacokinetics and pharmacodynamics of these compounds, especially soy isoflavones. While pharmacodynamics (the molecular mechanisms) of isoflavones are now well understood and reproducible, the data on pharmacokinetics of dietary isoflavones often appears inconsistent [15]. This review discusses the pharmacokinetics of isoflavones and about the factors that may influence the systemic bioavailability of dietary isoflavones.

\section{Fate of Dietary Isoflavones in the Gastrointestinal Tract}

Dietary isoflavones are absorbed into systemic circulation from gastrointestinal tract. It appears that glycosylated soy isoflavones are not absorbed intact from the gastrointestinal tract [16,17], and are absorbed only after deglycosylation to the aglycone form [18,19]. But puerarin (daidzein-8-C-glucoside), the major bioactive isoflavone of kudzu root, does not undergo significant de glycosylation and is thought to be absorbed intact via intestinal glucose transporters $[7,20]$.

A. Isoflavone ring system showing the ring nomenclature and numbering<smiles>O=c1c(-c2ccccc2)coc2ccccc12</smiles>

B. Structures of Isoflavones discussed in this article

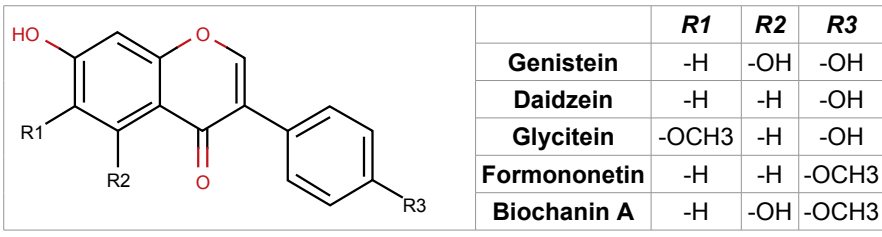

Table 1: Position of Ring $A$ in the isoflavone ring.

*Corresponding author: Sabarinath Chandrasekharan, Department of Biotechnology, PSG College of Technology, Peelamedu, Coimbatore, Tamil nadu 641006, India, Tel: 919894359811; E-mail: csab@bio.psgtech.ac.in

Received February 13, 2013; Accepted April 18, 2013; Published April 26, 2013

Citation: Chandrasekharan S, Aglin A (2013) Pharmacokinetics of Dietary Isoflavones. J Steroids Hormon Sci S12: 004. doi:10.4172/2157-7536.S12-004

Copyright: @ 2013 Chandrasekharan S, et al. This is an open-access article distributed under the terms of the Creative Commons Attribution License, which permits unrestricted use, distribution, and reproduction in any medium, provided the original author and source are credited. 
The conversion of glycosylated isoflavones to de glycosylated isoflavones begins in the oral cavity, wherein oral microflora and oral epithelium exhibit $\beta$-glucosidase activity [21]. In the upper small intestine, conversion to aglycone form continues by the action of intestinal lactase phlorizin hydrolase $[18,22]$, enterocytic $\beta$-glucosidase [19] and by microbial $\beta$-glucosidases [23,24].

Lactase phlorizin hydrolase, commonly known as lactase (E.C=3.2.1.108), is a membrane bound enzyme on the luminal side of the intestinal brush border and hydrolyses the glycosylated isoflavones to aglycones that diffuses into the enterocytes [18]. In absence or reduced activity of intestinal lactase phlorizin hydrolase, the glycosylated isoflavones reach the large intestine, where they are converted to the respective aglycone form by the resident intestinal microflora.

The anaerobic condition in the large intestine also favors reductive reactions on the isoflavones by the microbial flora [1,23]. Under the anaerobic, reductive conditions of the colon, genistein is reduced to dihydrogenistein and further to 5-hydroxyequol [25], while daidzein is reduced to dihydrodaidzein and equol [26]. Further, microbial cleavage of the Ring-C of isoflavones produces deoxybenzoin metabolites (DOBs), which are passively absorbed and have biological activity similar to isoflavones $[27,28]$.

Inter-individual and racial variations exist in the level and activity of intestinal lactase phlorizin hydrolase [29-32]. Lactase persistence or continued production of lactase into adulthood is common in individuals of European descent, while its frequency is low in EastAsian populations [30,31]. Therefore in individuals with reduced lactase activity, larger proportion of dietary isoflavones is subjected to microbial metabolism in the intestine, reducing the amount of intact isoflavone absorbed and consequently increasing the amount of microbial metabolites absorbed.

A biologically significant product from microbial metabolism of isoflavone is equol [26,33]. Daidzein on metabolism by specific bacterial consortia in the large intestine produces $\mathrm{S}(-)$ equol and $\mathrm{O}$-desmethylangolensin (O-DMA) which are absorbed into systemic circulation by passive diffusion $[4,34]$. Significantly, S(-)equol is more estrogenic than daidzein itself $[34,35]$. Considerable variability exists in the effectiveness of these specific bacterial consortia, and approximately $30 \%-50 \%$ of human population can produce equol following a soy based diet, and approximately $80 \%-90 \%$ can produce O-DMA [36]. Similarly, the ability to metabolize daidzein to equol appears to be higher in populations who routinely included soya based foods in their regular diet [26].

A recent study suggests that specific interactions between the human host and the intestinal microflora may exist in equol producing individuals, which may explain the variability between "equol producers" and "equol non-producers" in a given population [37]. Several species of bacteria isolated from fecal matter of "equol producers" have shown ability to convert daidzein to equol, under in vitro conditions [35]. The equol production status of an individual may vary over a period of time, subject to events such as antibiotic therapy and diet which may alter the nature and population of equol producing microflora in the gut $[38,39]$. Genistein can be converted to 5 -hydroxyequol by microbial metabolism, but evidence for production 5 -hydroxyequol in human subjects is yet to be reported [40].

Although microbial production of equol remains an important field of interest, DOBs such as O-DMA from daidzein and 6'-hydroxyO-desmethylangolensin (6'-O-DMA) from genistein are biologically significant due their weak estrogenic effect [41]. Several bacterial isolates from human gut have shown to anaerobically cleave the Ring-C of the isoflavones to produce O-DMA and 6'-O-DMA [25,27,28,42]. Further microbial metabolism of the O-DMA does not occur, as it does not possess a hydroxyl group on position 6' (position 5 on daidzein Ring-A), while in case of 6'-O-DMA, the methyl ethanone bridge is hydrolyzed between position 1 and 1' to produce 4-hydroxyphenyl2-propionic acid and 1,3,5-trihydroxybenzene [25,28,43]. Microbial metabolism of genistein and daidzein is represented in figure 1.

Intestinal microflora is also reported to perform 4'-O-demethylation of Biochanin A and formononetin to produce genistein and daidzein respectively, but to a lesser extent than liver microsomes [6]. The structure of the isoflavone appears to influence the susceptibility to microbial metabolism. The isoflavones with hydroxyl groups at 5,7 or 4' positions appears to be more susceptible to microbial metabolism than those without hydroxyl substitutions at these positions [20].

Therefore, the availability of a particular dietary isoflavone in the gut of an individual appears to be influenced by i) lactase persistence ii) the nature and population of the gut microbial flora of the individual. Both these factors influence the amount of intact isoflavone aglycone available for absorption by passive diffusion into intestinal epithelium. Infants and neonates may not have fully developed microflora and are therefore the role of microbial de-glycosylation and further metabolism of dietary isoflavones in the intestinal lumen appears to be limited $[44,45]$.

In addition, deglucuronidation of isoflavone conjugates can be carried out by intestinal microflora, and relevance of this is discussed below.

\section{Oral Bioavailability of Isoflavones}

Bioavailability of nutrients is defined as the "the proportion of a nutrient capable of being absorbed and available for use or storage" [46] and depends upon the factors affecting its absorption, distribution, metabolism and elimination kinetics.

After consumption, glycosylated isoflavones are rapidly deglycosylated, absorbed and metabolized in intestinal enterocytes and liver, entering the systemic circulation predominantly as conjugates with limited bioavailability. For example, "free" genistein aglycone typically represents only $1-3 \%$ of total plasma genistein [47]. The mean time to attain peak plasma concentrations $\left(t_{\max }\right)$ for the total (conjugated + unconjugated) genistein and daidzein is approximately 5-6 and 6-8 hours in humans $[48,49]$. In humans, the systemic bioavailability, as measured in terms of Area Under Curve (AUC), of genistein (mean $\mathrm{AUC}=4.54 \mu \mathrm{g} /(\mathrm{mL} . \mathrm{h})$ ) is greater than that of daidzein (mean AUC $=2.94 \mu \mathrm{g} /(\mathrm{mL} . \mathrm{h})$ ) [49]. Other pharmacokinetic studies [50,51] have reported similar values.

The extent of isoflavone absorption appears to be similar, irrespective of the glycone or aglycone nature of the isoflavone source $[23,24,52,53]$, although a slight delay in the onset of absorption is expected due to microbial deglycosylation required for glycosylated sources [19]. In addition to the status of glycosylation, the absorption is reported to be affected by other contents of diet, especially the dietary fiber content [54-56]. Bioavailability is increased by a rapid gut transit time and by low fecal digestion rates and is decreased by a fiber-rich $\operatorname{diet}[54,57,58]$. 
<smiles>O=c1c(-c2ccc(O)cc2)coc2cc(O)cc(O)c12</smiles>

Genistein<smiles>CC(C)CCOc1cc(O)cc(O)c1C(=O)C1COc2ccccc21</smiles>

Dihydrogenistein<smiles>CCOc1cc(O)cc(O)c1C(=O)C(C)c1ccc(O)cc1</smiles>

6'-hydroxy-O-DMA<smiles>O=C(O)C1C(O)=CC(O)=CC1O</smiles>

1,3,5-Trihydroxybenzene<smiles>C1CCCCC1</smiles><smiles>O=c1c(-c2ccc(O)cc2)coc2cc(O)ccc12</smiles>

Dadzein<smiles>COCCOc1cc(O)ccc1C1COCCO1</smiles>

Dihydrodaidzein

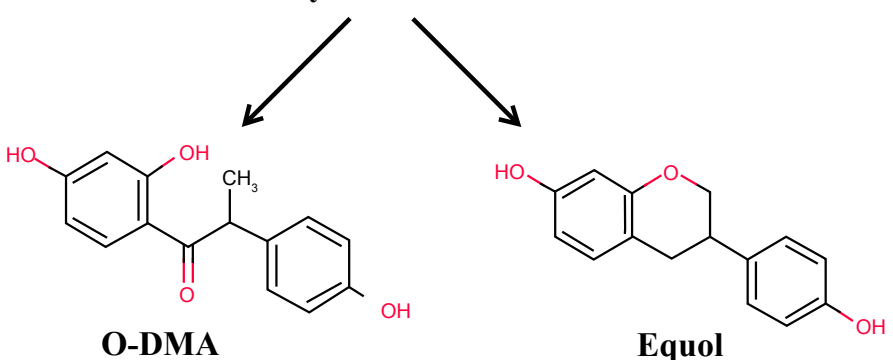

Equol<smiles>CC(C(=O)O)c1ccc(O)cc1</smiles>

\section{4-hydroxypheny1- \\ 2-propionic acid}

Figure 1: Metabolism of genistein and daidzein by gut microflora.

\section{Distribution}

Isoflavones are rapidly distributed to all tissues and crosses placental barrier and blood brain barrier $[59,60]$. The volume of distribution $\left(V_{d}\right)$ of daidzein is found to be greater than that of genistein $[48,55]$. In a human study involving radiolabelled isoflavones, it was found that the mean volume of distribution normalized to bioavailability $\left(V_{d} / F\right)$, clearance rate, and half-life of $\left[{ }^{13} \mathrm{C}\right]$ daidzein were $336.25 \mathrm{~L}, 30.09 \mathrm{~L} / \mathrm{h}$, and $7.75 \mathrm{~h}$, respectively; the corresponding values for $\left[{ }^{13} \mathrm{C}\right]$ genistein were $258.76 \mathrm{~L}, 21.85 \mathrm{~L} / \mathrm{h}$, and $7.77 \mathrm{~h}$ [48]. Similar values have been reported in several other pharmacokinetic studies [50,51].

Humans consuming three meals containing soy milk on a daily basis may have serum genistein concentrations up to $4.6 \mu M$ [56], and human infants fed soy-based infant formula may have plasma genistein levels between 1.5 and $4.4 \mu M$ [45]. Postmenopausal women consuming soy isoflavone supplements as an alternative to hormone replacement therapy can show serum levels in the range of 5-10 $\mu \mathrm{M}[49,50]$.

Isoflavones are also distributed to the extra-vascular compartments. Placental transfer of isoflavones from dietary sources has been demonstrated in animal models[59,61-63] and human volunteers $[64,65]$. Isoflavones are also reported in the amniotic fluid, in expectant mothers on soy based diet $[64,66]$. Prostate is reported to achieve higher-than-serum concentration of isoflavones in males consuming soy rich food [67].

\section{Metabolism}

The metabolism of isoflavones closely mimic the metabolism of endogenous estrogens, with phase-II conjugative reactions predominant than phase-I reactions. The isoflavone aglycones, including equol, which passively diffuses into the intestinal cells are rapidly conjugated into sulfate or glucuronide conjugates, such that only $1-3 \%$ of isoflavones in the aglycone form reaches the systemic circulation $[47,68,69]$.

UDP glucuronosyltransferase (UGT) and sulfotransferase (SULT) are the key enzymes involved in the phase-II conjugative reactions with isoflavones [70]. These reactions occurs mainly in the intestinal microsomes, concurrent with the absorption, but hepatic isoforms are also active [71,72]. Therefore, the extent of first-pass metabolism is very high $(>90 \%)$ for isoflavones like genistein and daidzein before they enter into the general circulation.

UGT mediated glucuronidation seems to be the predominant phase-II conjugative reaction, and the glucuronide conjugate levels are higher than the sulphate conjugates $[70,73,74]$. Several isoforms of UGTs (1A1, 1A3, 1A4, 1A5, 1A6, 1A7, 1A8, 1A9, 1A10, 2B4, 2B7, 2B10, 
$2 \mathrm{~B} 11,2 \mathrm{~B} 15$, and 2B17) exist $[70,71,75]$. Most of the UGT isoforms are present in several organs, including intestine, kidneys and liver, but their distribution and levels shows variation [75]. UGT1A1 is expressed in all the organs although its expression in the liver appeared to be more pronounced than that in the intestine, UGT1A9 is only expressed in liver whereas UGT1A8 and UGT1A10 are mostly expressed in the small intestine [75].

UGT isoforms are reported to catalyze glucuronide conjugation at the 7 and 4' position of genistein and daidzein [70,71]. UGT1A1, 1A8, $1 \mathrm{~A} 9$ and $1 \mathrm{~A} 10$ were identified to be the major isoforms responsible for glucuronide conjugation of genistein, glycitein, biochanin A, prunetin, formononetin and daidzein [72]. Polymorphisms in UGT has also been reported, which may result in inter-individual differences in isoflavone conjugation rates and extents [76,77].

Sulphation of isoflavones are catalyzed by the SULT isoforms, especially SULT $1 \mathrm{~A} 1^{\star} 2,1 \mathrm{E}$, and $2 \mathrm{~A} 1$ in intestine and liver $[70,78]$. SULT1A1 and SULT1E1 are reported to be important in regioselective mono- and di-sulfation reactions of isoflavones [79]. Sulphoglucuronide conjugates of isoflavones are also produced, by a combined or sequential action of UGTs and SULTs [73].

Isoflavones undergo phase-I metabolism too, although to a lesser extent than the phase-II conjugative reactions $[5,73]$. Hydroxylation reactions appears to be the main Phase-I reaction of isoflavones occurring in the liver [80,81].

The conjugated isoflavones are secreted in the bile and are released into the upper small intestinal tract, wherein microbial deconjugation and subsequent reabsorption of the isoflavones occurs. This process, known as entero-hepatic recycling, can significantly increase the residence time of the isoflavones in the body $[82,83]$. In addition to the entero-hepatic recycling, enteric recycling - wherein the intestinal enterocytes excrete the isoflavone conjugates back into the intestinal lumen may also significantly influence the disposition and bioavailability of isoflavones $[82,84]$.

Efflux transporters such as multidrug resistance proteins (MRP1 and MRP2) and breast cancer resistance proteins (BCRP) are involved in entero-hepatic recycling and enteric recycling of isoflavones $[77,85,86]$ and can be subject to genetic polymorphisms $[77,87]$. A recent study with BCRP knock-out (-/-) mice have shown that mice lacking BRCP show significantly reduced intestinal and biliary excretion of isoflavone conjugates, when compared to the wild-type mice [88]. A similar study with MRP2 deficient mutant mice reported a higher plasma concentration of genistein and daidzein following oral administration, partly due to reduced biliary excretion [87]. The inter-person variations in the efflux transporter expression and activity may cause marked variations in the intestinal disposition of dietary isoflavones [86,87]. A single nucleotide polymorphism (rs12762549) in MRP2 gene, was reported to be associated with inter-individual variation of plasma level of isoflavone metabolites in humans [87].

\section{Elimination}

Approximately $10-60 \%$ of the dietary isoflavones is excreted in urine and constitutes the main route for elimination of isoflavones. The urinary excretion proportions varies with the isoflavone nature; for example, the urinary excretion of daidzein is higher than that of genistein and glycitein [51,89]. Glucuronide conjugates account for the majority $(70-90 \%)$ of the isoflavone content in urine, followed by sulphate conjugates (10-25\%) and aglycone forms (1-10\%) [89]. The peak urinary elimination appears to be 7-8 hours after a isoflavone rich meal [51] and majority of the elimination occurs within 24 hours of the meal, with an elimination 8-10 hours [90].

Fecal elimination is a minor route, accounting for $1-4 \%$ of the dietary isoflavone consumption [51], with the aglycone form accounting for the majority ( $>80 \%$ ) of the fecal isoflavone content [91]. Isoflavones from the diet appears in the breast milk [45,92], amniotic fluid [64] and prostatic fluid [93].

The biological fate of dietary isoflavones is schematically summarized in figure 2 .

\section{Biological Activities of Isoflavones}

Isoflavones can produce both potentially beneficial and deleterious effects in humans by interacting with various cellular receptors, metabolites and enzymes. Isoflavones possess structural and functional features which resembles estrogens, namely, the terminal phenolic groups and therefore can act as estromimetics in metazoans [94]. Isoflavones are weak to moderate phytoestrogens, and can potentially modulate estrogenic responses through interaction with estrogen receptors [95]. As estromimetics, they can act as agonists on cellular estrogen receptors and thereby modulate estrogen-mediated cellular functions such as proliferation and apoptosis in cells abundant in estrogen receptors such as breast and prostate.

Two major subtypes of estrogen receptors are reported in humans, $v i z$. estrogen receptor-alpha (ER $\alpha)$ and estrogen receptor-beta (ER $\beta)$. Agonists of ERa generally causes cell proliferation (for example, in breast cells), while ER $\beta$ agonists causes cell cycle arrest (for example, in prostate cells) and apoptosis $[95,96]$. This estromimetic effect of isoflavones, especially soy isoflavones, are therefore reported to be correlated to lower incidences of cancers, such as prostate cancer, in populations which consumes regular quantities of isoflavone-rich food $[97,98]$.

In addition to the estrogenic effects, isoflavones may also have effects on other physiological systems. Isoflavones and their oxidative metabolites are reported to have anti-oxidant and free radical scavenging properties at physiological concentrations [99-101]. Isoflavones may reduce low-density lipoprotein (LDL) cholesterol in serum and thereby provide beneficial effects to overall cardiac functioning, presumably due their estrogenic effects on lipid peroxidation.

In addition to the above mentioned beneficial biological effects, isoflavones may also show potentially deleterious effects on cells, by virtue of their ability to inhibit key enzymes such as topoisomerases and kinases. Genistein is reported to be a potent inhibitor of topoisomerase II [102,103]. Inhibition of Topoisomerase II is reported to cause cleavage of MLL (myeloid-lymphoid leukemia) genes in utero and thereby cause an increased risk of acute myeloid leukemia and of acute lymphoid leukemia in infants [104-106]. Soy isoflavones, especially genistein, is a potent inhibitor of tyrosine kinases [107,108]. Soy isoflavones are reported to interfere with thyroid peroxidase involved in the formation of thyroid hormones $[109,110]$. Soy based foods were reported to increase the risk of hyperthyroidism [111], but this effect can be prevented with concurrent intake of Iodine [112,113].

These physiological effects, both beneficial and deleterious, of isoflavones are therefore dependent upon the plasma concentration and persistence of isoflavones (as aglycones) at the target organ [114]. The conjugated isoflavones do not easily diffuse across the cell membrane and therefore possess only weak cellular activities when compared to aglycone forms [74]. Therefore, the factors modifying 


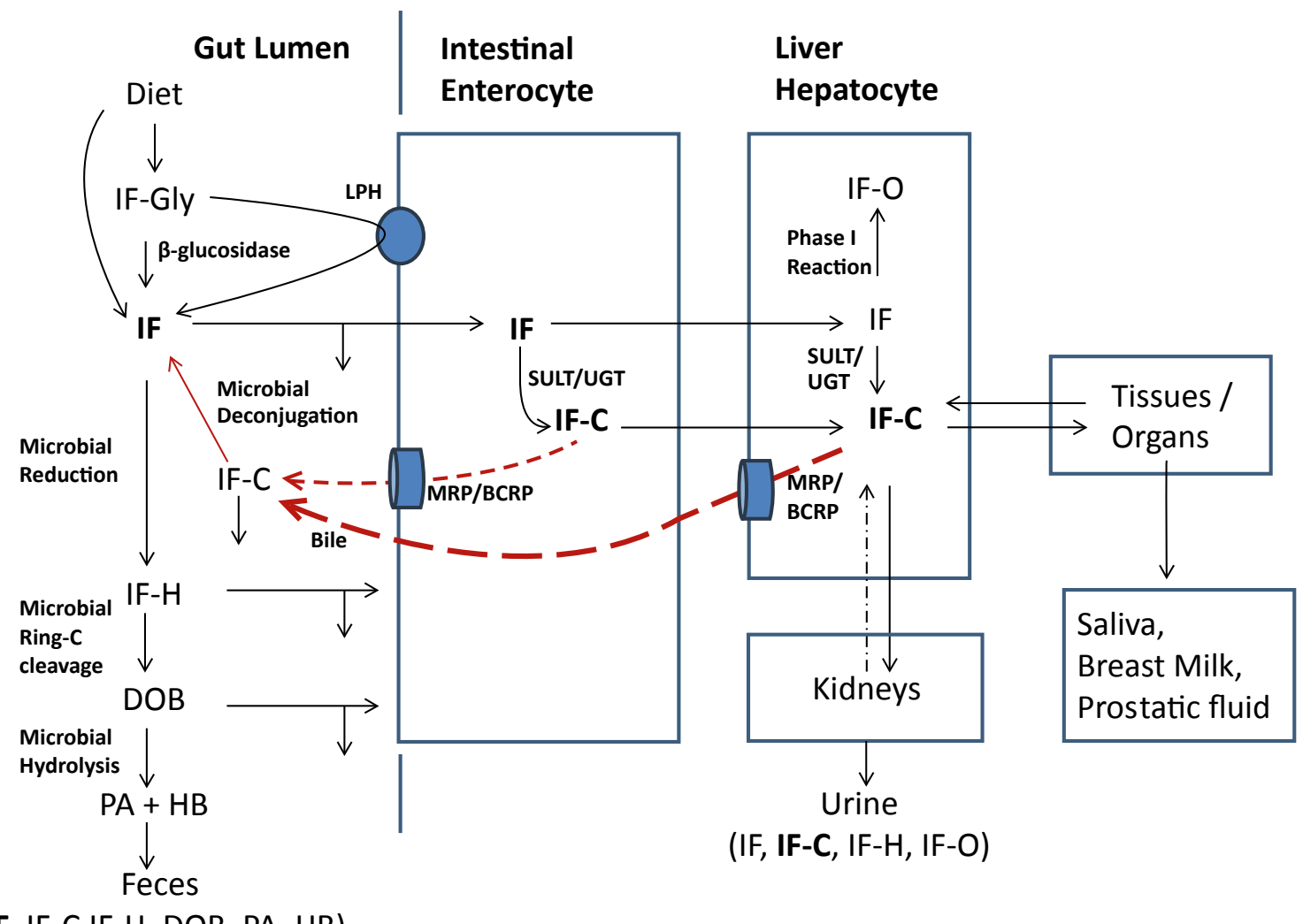

(IF, IF-C,IF-H, DOB, PA, HB)

Figure 2: Fate of dietary isoflavones in human body. In each compartment, the most predominant component is indicated in bold format. Enteric recycling and enterohepatic recycling are represented by broken arrows. Abbreviations used in this figure; isoflavone glycoside (IF-Gly), Isoflavone aglycone (IF), isoflavone conjugate (IF-C), reduced isoflavone (IF-H), oxidized isoflavone (IF-O), deoxybenzoins (DOB), propionic acid derivative (PA), hydroxyl benzene derivative (HB), lactase phlorizin hydrolase (LPH), sulfotransferase (SULT), UDP glucuronosyltransferase (UGT), multidrug resistance protein (MRP) and breast cancer resistance proteins (BCRP).

pharmacokinetics (absorption, distribution, disposition, metabolism and elimination) of the oral isoflavones are important in maintaining the balance between beneficial and adverse effects of the isoflavones.

\section{Challenges and Conclusion}

Extrapolating the effect of isoflavones from in vitro studies to humans is often complicated. For example, genistein aglycone produces rapid cell arrest and apoptosis of prostate cancer lines at micromolar concentration $[115,116]$, but these effects are difficult to reproduce in metazoans because the serum levels of aglycones are in nanomolar levels $[11,117]$. The high rates of conjugative metabolism and resultant low levels of systemic aglycones leads to reduced pharmacological effects of isoflavones [23].

Studies with animal models provide valuable pharmacokinetic data, especially information about the metabolism and disposition patterns of a test compound. Rodent models have been used extensively for understanding the pharmacokinetics and pharmacodynamics of isoflavones $[78,83,115]$. But some studies $[118,119]$ have shown that rodents (and other species) show marked differences in the metabolic pattern of isoflavones, which may have implications on selecting a suitable animal model for such studies [119].

Meta-analysis and interpreting the outcomes from multiple studies involving benefits (and risks) of dietary isoflavones is a challenge for researchers and regulatory authorities. For example, European Food Safety Authority recently rejected a number of beneficial claims on soy products, including reduction of serum LDL concentrations, menopausal symptoms, cardiovascular health and hair growth, citing lack of substantial correlation between the consumption of soy and the study outcomes [120,121]. In 1999, United States Food and Drug Administration gave approval for labeling foods with soy proteins as being protective against coronary heart disease, based on outcomes of 38 clinical studies showing that consumption of at least 25 grams of soy per day lowered total and LDL cholesterol [122]. Further studies have confirmed this LDL lowering effect [123], while other studies have challenged the significance of the extent of LDL lowering and coronary risk [124]. Similarly, the extent of beneficial effects provided by dietary soy isoflavones on prostate cancer $[97,98]$ is disputed by some studies $[125,126]$. These variations in study outcomes indicate that significant inter-individual variations exist in the pharmacokinetics and pharmacodynamics of isoflavones from dietary sources.

In summary, from a pharmacokinetic point of view, the bioavailability of isoflavones is subject to several factors that contributes to the inter-person variability observed i) variability in the isoflavone content in the food ii) availability of isoflavones from the food matrix iii) lactase persistence status of the test population iv) variations in the gastrointestinal microflora $v$ ) inherent variations in the gastric transit times vi) genetic variations in the systemic metabolic rates. Therefore including these factors into analysis of the study outcomes may help in better interpretation of such studies. 


\section{Acknowledgment}

The authors wish to thank the Management, PSG College of Technology, Coimbatore, for their support.

\section{References}

1. Barnes S (2010) The biochemistry, chemistry and physiology of the isoflavones in soybeans and their food products. Lymphat Res Biol 8: 89-98.

2. Boué SM, Wiese TE, Nehls S, Burow ME, Elliott S, et al. (2003) Evaluation of the estrogenic effects of legume extracts containing phytoestrogens. J Agric Food Chem 51:2193-2199.

3. Coward L, Barnes NC, Setchell KDR, Barnes S (1993) Genistein, daidzein, and their beta.-glycoside conjugates: antitumor isoflavones in soybean foods from American and Asian diets. J Agric Food Chem 41:1961-1967.

4. Axelson M, Sjövall J, Gustafsson BE, Setchell KD (1984) Soya--a dietary source of the non-steroidal oestrogen equol in man and animals. J Endocrinol 102: 49-56.

5. Heinonen SM, Hoikkala A, Wähälä K, Adlercreutz H (2003) Metabolism of the soy isoflavones daidzein, genistein and glycitein in human subjects. Identification of new metabolites having an intact isoflavonoid skeleton. J Steroid Biochem Mol Biol 87: 285-299.

6. Tolleson WH, Doerge DR, Churchwell MI, Marques MM, Roberts DW (2002) Metabolism of biochanin $\mathrm{A}$ and formononetin by human liver microsomes in vitro. J Agric Food Chem 50: 4783-4790.

7. Prasain JK, Jones K, Brissie N, Moore R, Wyss JM, et al. (2004) Identification of puerarin and its metabolites in rats by liquid chromatography-tandem mass spectrometry. J Agric Food Chem 52: 3708-3712.

8. Setchell KD (2000) Absorption and metabolism of soy isoflavones-from food to dietary supplements and adults to infants. J Nutr 130: 654S-5S.

9. Wang HJ, Murphy PA (1996) Mass Balance Study of Isoflavones during Soybean Processing. J Agric Food Chem 44 : 2377-2383.

10. Messina M, Bennink M (1998) Soyfoods, isoflavones and risk of colonic cancer: a review of the in vitro and in vivo data. Baillieres Clin Endocrinol Metab 12 707-728.

11. Adlercreutz $\mathrm{H}$, Markkanen $\mathrm{H}$, Watanabe S (1993) Plasma concentrations of phyto-oestrogens in Japanese men. Lancet 342: 1209-1210.

12. Adlercreutz H (1998) Epidemiology of phytoestrogens. Baillieres Clin Endocrino Metab 12: 605-623.

13. Stephens FO (1997) Breast cancer: aetiological factors and associations (a possible protective role of phytoestrogens). Aust N Z J Surg 67: 755-760.

14. Tham DM, Gardner CD, Haskell WL (1998) Clinical review 97: Potential health benefits of dietary phytoestrogens: a review of the clinical, epidemiological, and mechanistic evidence. J Clin Endocrinol Metab 83: 2223-2235.

15. Larkin T, Price WE, Astheimer L (2008) The key importance of soy isoflavone bioavailability to understanding health benefits. Crit Rev Food Sci Nutr 48: 538552.

16. Piskula MK, Yamakoshi J, Iwai Y (1999) Daidzein and genistein but not their glucosides are absorbed from the rat stomach. FEBS Lett 447: 287-291.

17. Setchell KD, Brown NM, Zimmer-Nechemias L, Brashear WT, Wolfe BE, et al (2002) Evidence for lack of absorption of soy isoflavone glycosides in humans supporting the crucial role of intestinal metabolism for bioavailability. Am J Clin Nutr 76: 447-453.

18. Day AJ, Cañada FJ, Díaz JC, Kroon PA, Mclauchlan R, et al. (2000) Dietary flavonoid and isoflavone glycosides are hydrolysed by the lactase site of lactase phlorizin hydrolase. FEBS Lett 468: 166-170.

19. Day AJ, DuPont MS, Ridley S, Rhodes M, Rhodes MJ, et al. (1998) Deglycosylation of flavonoid and isoflavonoid glycosides by human small intestine and liver beta-glucosidase activity. FEBS Lett 436: 71-75.

20. Simons AL, Renouf M, Hendrich S, Murphy PA (2005) Human gut microbia degradation of flavonoids: structure-function relationships. J Agric Food Chem 53: 4258-4263.

21. Walle T, Browning AM, Steed LL, Reed SG, Walle UK (2005) Flavonoid glucosides are hydrolyzed and thus activated in the oral cavity in humans. $J$ Nutr 135: 48-52.
22. Wilkinson AP, Gee JM, Dupont MS, Needs PW, Mellon FA, et al. (2003) Hydrolysis by lactase phlorizin hydrolase is the first step in the uptake of daidzein glucosides by rat small intestine in vitro. Xenobiotica 33: 255-264.

23. D'Archivio M, Filesi C, Varì R, Scazzocchio B, Masella R (2010) Bioavailability of the polyphenols: status and controversies. Int J Mol Sci 11: 1321-1342.

24. Rowland I, Faughnan M, Hoey L, Wähälä K, Williamson G, et al. (2003) Bioavailability of phyto-oestrogens. Br J Nutr 89 Suppl 1: S45-58.

25. Matthies A, Clavel T, Gütschow M, Engst W, Haller D, et al. (2008) Conversion of daidzein and genistein by an anaerobic bacterium newly isolated from the mouse intestine. Appl Environ Microbiol 74: 4847-4852.

26. Yuan JP, Wang JH, Liu X (2007) Metabolism of dietary soy isoflavones to equo by human intestinal microflora--implications for health. Mol Nutr Food Res 51 765-781.

27. Hur HG, Beger RD, Heinze TM, Lay JO Jr, Freeman JP, et al. (2002) Isolation of an anaerobic intestinal bacterium capable of cleaving the C-ring of the isoflavonoid daidzein. Arch Microbiol 178: 8-12.

28. Schoefer L, Mohan R, Braune A, Birringer M, Blaut M (2002) Anaerobic C-ring cleavage of genistein and daidzein by Eubacterium ramulus. FEMS Microbio Lett 208: 197-202

29. Bodlaj G, Stöcher M, Hufnagl P, Hubmann R, Biesenbach G, et al. (2006) Genotyping of the lactase-phlorizin hydrolase -13910 polymorphism by LightCycler PCR and implications for the diagnosis of lactose intolerance. Clin Chem 52: 148-151.

30. Friedrich DC, Santos SE, Ribeiro-dos-Santos ÂK, Hutz MH (2012) Severa different lactase persistence associated alleles and high diversity of the lactase gene in the admixed Brazilian population. PLoS One 7: e46520.

31. Itan Y, Jones BL, Ingram CJ, Swallow DM, Thomas MG (2010) A worldwide correlation of lactase persistence phenotype and genotypes. BMC Evol Bio 10: 36 .

32. Kuokkanen M, Enattah NS, Oksanen A, Savilahti E, Orpana A, et al. (2003) Transcriptional regulation of the lactase-phlorizin hydrolase gene by polymorphisms associated with adult-type hypolactasia. Gut 52: 647-652.

33. Axelson M, Kirk DN, Farrant RD, Cooley G, Lawson AM, et al. (1982) The identification of the weak oestrogen equol [7-hydroxy-3-(4'-hydroxyphenyl) chroman] in human urine. Biochem J 201: 353-357.

34. Setchell KD, Brown NM, Lydeking-Olsen E (2002) The clinical importance of the metabolite equol-a clue to the effectiveness of soy and its isoflavones. Nutr 132: 3577-3584.

35. Setchell KD, Clerici C (2010) Equol: history, chemistry, and formation. J Nut 140: $1355 \mathrm{~S}-62 \mathrm{~S}$

36. Atkinson C, Frankenfeld CL, Lampe JW (2005) Gut bacterial metabolism of the soy isoflavone daidzein: exploring the relevance to human health. Exp Biol Med (Maywood) 230: 155-170.

37. Hong KW, Ko KP, Ahn Y, Kim CS, Park SJ, et al. (2012) Epidemiological profiles between equol producers and nonproducers: a genomewide association study of the equol-producing phenotype. Genes Nutr 7: 567-574.

38. Franke AA, Lai JF, Halm BM, Pagano I, Kono N, et al. (2012) Equol production changes over time in postmenopausal women. J Nutr Biochem 23: 573-579.

39. Franke AA, Lai JF, Pagano I, Morimoto Y, Maskarinec G (2012) Equo production changes over time in pre-menopausal women. Br J Nutr 107: 1201 1206

40. Matthies A, Loh G, Blaut M, Braune A (2012) Daidzein and genistein are converted to equol and 5-hydroxy-equol by human intestinal Slackia isoflavoniconvertens in gnotobiotic rats. J Nutr 142: 40-46.

41. Frankenfeld CL (2011) O-desmethylangolensin: the importance of equol's lesser known cousin to human health. Adv Nutr 2: 317-324

42. Blaut M, Schoefer L, Braune A (2003) Transformation of flavonoids by intestina microorganisms. Int J Vitam Nutr Res 73: 79-87.

43. Rechner AR, Smith MA, Kuhnle G, Gibson GR, Debnam ES, et al. (2004 Colonic metabolism of dietary polyphenols: influence of structure on microbial fermentation products. Free Radic Biol Med 36: 212-225.

44. Chen A, Rogan WJ (2004) Isoflavones in soy infant formula: a review of evidence for endocrine and other activity in infants. Annu Rev Nutr 24: 33-54. 
45. Setchell KD, Zimmer-Nechemias L, Cai J, Heubi JE (1997) Exposure of infants to phyto-oestrogens from soy-based infant formula. Lancet 350: 23-27.

46. Srinivasan VS (2001) Bioavailability of nutrients: a practical approach to in vitro demonstration of the availability of nutrients in multivitamin-mineral combination products. J Nutr 131: 1349S-50S.

47. Patisaul HB, Jefferson W (2010) The pros and cons of phytoestrogens. Fron Neuroendocrinol 31: 400-419.

48. Setchell KD, Faughnan MS, Avades T, Zimmer-Nechemias L, Brown NM, et al. (2003) Comparing the pharmacokinetics of daidzein and genistein with the use of 13C-labeled tracers in premenopausal women. Am J Clin Nutr 77: 411-419.

49. Setchell KD, Brown NM, Desai P, Zimmer-Nechemias L, Wolfe BE, et al. (2001) Bioavailability of pure isoflavones in healthy humans and analysis of commercial soy isoflavone supplements. J Nutr 131: 1362S-75S.

50. Bloedon LT, Jeffcoat AR, Lopaczynski W, Schell MJ, Black TM, et al (2002) Safety and pharmacokinetics of purified soy isoflavones: single-dose administration to postmenopausal women. Am J Clin Nutr 76: 1126-1137.

51. Watanabe S, Yamaguchi M, Sobue T, Takahashi T, Miura T, et al. (1998) Pharmacokinetics of soybean isoflavones in plasma, urine and feces of men after ingestion of $60 \mathrm{~g}$ baked soybean powder (kinako). J Nutr 128: 1710-1715.

52. Maskarinec G, Watts K, Kagihara J, Hebshi SM, Franke AA (2008) Urinary isoflavonoid excretion is similar after consuming soya milk and miso soup in Japanese-American women. Br J Nutr 100: 424-429.

53. Zubik L, Meydani M (2003) Bioavailability of soybean isoflavones from aglycone and glucoside forms in American women. Am J Clin Nutr 77: 1459-1465.

54. Nielsen IL, Williamson $G$ (2007) Review of the factors affecting bioavailability of soy isoflavones in humans. Nutr Cancer 57: 1-10.

55. Teekachunhatean S, Techatoei S, Rojanasthein N, Manorot M, Sangdee C (2012) Influence of fructooligosaccharide on pharmacokinetics of isoflavones in postmenopausal women. Evid Based Complement Alternat Med 2012: 783802.

56. Xu X, Harris KS, Wang HJ, Murphy PA, Hendrich S (1995) Bioavailability of soybean isoflavones depends upon gut microflora in women. J Nutr 125: 2307 2315.

57. Zheng Y, Lee SO, Verbruggen MA, Murphy PA, Hendrich S (2004) The apparent absorptions of isoflavone glucosides and aglucons are similar in women and are increased by rapid gut transit time and low fecal isoflavone degradation. J Nutr 134: 2534-2539.

58. Zheng Y, Hu J, Murphy PA, Alekel DL, Franke WD, et al. (2003) Rapid gut transit time and slow fecal isoflavone disappearance phenotype are associated with greater genistein bioavailability in women. J Nutr 133: 3110-3116.

59. Doerge DR, Churchwell MI, Chang HC, Newbold RR, Delclos KB (2001) Placental transfer of the soy isoflavone genistein following dietary and gavage administration to Sprague Dawley rats. Reprod Toxicol 15: 105-110.

60. Gu L, Laly M, Chang HC, Prior RL, Fang N, et al. (2005) Isoflavone conjugates are underestimated in tissues using enzymatic hydrolysis. J Agric Food Chem 53: 6858-6863.

61. Doerge DR (2011) Bioavailability of soy isoflavones through placental/ lactational transfer and soy food. Toxicol Appl Pharmacol 254: 145-147.

62. Jefferson WN, Williams CJ (2011) Circulating levels of genistein in the neonate, apart from dose and route, predict future adverse female reproductive outcomes. Reprod Toxicol 31: 272-279.

63. Jefferson WN, Patisaul HB, Williams CJ (2012) Reproductive consequences of developmental phytoestrogen exposure. Reproduction 143: 247-260.

64. Adlercreutz H, Yamada T, Wähälä K, Watanabe S (1999) Maternal and neonatal phytoestrogens in Japanese women during birth. Am J Obstet Gynecol 180: 737-743.

65. Todaka E, Sakurai K, Fukata H, Miyagawa H, Uzuki M, et al. (2005) Fetal exposure to phytoestrogens--the difference in phytoestrogen status between mother and fetus. Environ Res 99: 195-203.

66. Jarrell J, Foster WG, Kinniburgh DW (2012) Phytoestrogens in human pregnancy. Obstet Gynecol Int 2012: 850313.

67. Gardner CD, Oelrich B, Liu JP, Feldman D, Franke AA, et al. (2009) Prostatic soy isoflavone concentrations exceed serum levels after dietary supplementation. Prostate 69: 719-726.
68. Wahajuddin, Taneja I, Arora S, Raju KS, Siddiqui N (2013) Disposition of Pharmacologically Active Dietary Isoflavones in Biological Systems. Curr Drug Metab .

69. Walsh KR, Failla ML (2009) Transport and metabolism of equol by Caco-2 human intestinal cells. J Agric Food Chem 57: 8297-8302.

70. Doerge DR, Chang HC, Churchwell MI, Holder CL (2000) Analysis of soy isoflavone conjugation in vitro and in human blood using liquid chromatographymass spectrometry. Drug Metab Dispos 28: 298-307.

71. Pritchett LE, Atherton KM, Mutch E, Ford D (2008) Glucuronidation of the soyabean isoflavones genistein and daidzein by human liver is related to levels of UGT1A1 and UGT1A9 activity and alters isoflavone response in the MCF-7 human breast cancer cell line. J Nutr Biochem 19: 739-745.

72. Tang L, Singh R, Liu Z, Hu M (2009) Structure and concentration changes affect characterization of UGT isoform-specific metabolism of isoflavones. Mol Pharm 6: 1466-1482

73. Heinonen SM, Wähälä K, Adlercreutz H (2002) Metabolism of isoflavones in human subjects. Phytochemistry Reviews 1: 175-182.

74. Zhang Y, Hendrich S, Murphy PA (2003) Glucuronides are the main isoflavone metabolites in women. J Nutr 133: 399-404.

75. Ohno S, Nakajin S (2009) Determination of mRNA expression of human UDP glucuronosyltransferases and application for localization in various human tissues by real-time reverse transcriptase-polymerase chain reaction. Drug Metab Dispos 37: 32-40.

76. Sugatani J (2012) Function, genetic polymorphism, and transcriptiona regulation of human UDP-glucuronosyltransferase (UGT) 1A1. Drug Metab Pharmacokinet

77. Wakeling LA, Ford D (2012) Polymorphisms in genes involved in the metabolism and transport of soy isoflavones affect the urinary metabolite profile in premenopausal women following consumption of a commercial soy supplement as a single bolus dose. Mol Nutr Food Res 56: 1794-1802.

78. Ronis MJ, Little JM, Barone GW, Chen G, Radominska-Pandya A, et al. (2006) Sulfation of the isoflavones genistein and daidzein in human and rat liver and gastrointestinal tract. J Med Food 9: 348-355.

79. Nakano H, Ogura K, Takahashi E, Harada T, Nishiyama T, et al. (2004) Regioselective monosulfation and disulfation of the phytoestrogens daidzein and genistein by human liver sulfotransferases. Drug Metab Pharmacokinet 19: 216-226.

80. Kulling SE, Honig DM, Metzler M (2001) Oxidative metabolism of the soy isoflavones daidzein and genistein in humans in vitro and in vivo. J Agric Food Chem 49: 3024-3033.

81. Rüfer CE, Maul R, Donauer E, Fabian EJ, Kulling SE (2007) In vitro and in vivo metabolism of the soy isoflavone glycitein. Mol Nutr Food Res 51: 813-823.

82. Chen J, Lin H, Hu M (2003) Metabolism of flavonoids via enteric recycling: role of intestinal disposition. J Pharmacol Exp Ther 304: 1228-1235.

83. Sfakianos J, Coward L, Kirk M, Barnes S (1997) Intestinal uptake and biliary excretion of the isoflavone genistein in rats. J Nutr 127: 1260-1268.

84. Wu B, Kulkarni K, Basu S, Zhang S, Hu M (2011) First-pass metabolism via UDP-glucuronosyltransferase: a barrier to oral bioavailability of phenolics. J Pharm Sci 100: 3655-3681.

85. Jia X, Chen J, Lin H, Hu M (2004) Disposition of flavonoids via enteric recycling: enzyme-transporter coupling affects metabolism of biochanin $A$ and formononetin and excretion of their phase II conjugates. J Pharmacol Exp Ther 310: 1103-1113.

86. Wang SW, Chen J, Jia X, Tam VH, Hu M (2006) Disposition of flavonoids via enteric recycling: structural effects and lack of correlations between in vitro and in situ metabolic properties. Drug Metab Dispos 34: 1837-1848.

87. Kato K, Kusuhara H, Kumagai Y, leiri I, Mori H, et al. (2012)Association of multidrug resistance-associated protein 2 single nucleotide polymorphism rs 12762549 with the basal plasma levels of phase II metabolites of isoflavonoids in healthy Japanese individuals. Pharmacogenet Genomics 22: 344-354.

88. Yang Z, Zhu W, Gao S, Yin T, Jiang W, et al. (2012) Breast cancer resistance protein (ABCG2) determines distribution of genistein phase II metabolites: reevaluation of the roles of $A B C G 2$ in the disposition of genistein. Drug Metab Dispos 40: 1883-1893. 
89. Shelnutt SR, Cimino CO, Wiggins PA, Badger TM (2000) Urinary pharmacokinetics of the glucuronide and sulfate conjugates of genistein and daidzein. Cancer Epidemiol Biomarkers Prev 9: 413-419.

90. Setchell KD, Brown NM, Desai PB, Zimmer-Nechimias L, Wolfe B, et al. (2003) Bioavailability, disposition, and dose-response effects of soy isoflavones when consumed by healthy women at physiologically typical dietary intakes. J Nutr 133: $1027-1035$

91. Adlercreutz H, Fotsis T, Kurzer MS, Wähälä K, Mäkelä T, et al. (1995) Isotope dilution gas chromatographic-mass spectrometric method for the determination of unconjugated lignans and isoflavonoids in human feces, with preliminary results in omnivorous and vegetarian women. Anal Biochem 225: 101-108.

92. Franke AA, Custer LJ, Tanaka Y (1998) Isoflavones in human breast milk and other biological fluids. Am J Clin Nutr 68: 1466S-1473S.

93. Morton MS, Matos-Ferreira A, Abranches-Monteiro L, Correia R, Blacklock N, et al. (1997) Measurement and metabolism of isoflavonoids and lignans in the human male. Cancer Lett 114: 145-151.

94. Andres S, Abraham K, Appel KE, Lampen A (2011) Risks and benefits of dietary isoflavones for cancer. Crit Rev Toxicol 41: 463-506.

95. Ascenzi P, Bocedi A, Marino M (2006) Structure-function relationship of estrogen receptor alpha and beta: impact on human health. Mol Aspects Med 27: 299-402.

96. Heldring N, Pike A, Andersson S, Matthews J, Cheng G, et al. (2007) Estrogen receptors: how do they signal and what are their targets. Physiol Rev 87: 905931.

97. Yan L, Spitznagel EL (2009) Soy consumption and prostate cancer risk in men: a revisit of a meta-analysis. Am J Clin Nutr 89: 1155-1163.

98. Yan L, Spitznagel EL (2005) Meta-analysis of soy food and risk of prostate cancer in men. Int J Cancer 117: 667-669.

99. Ng LT, Ko HH, Lu TM (2009) Potential antioxidants and tyrosinase inhibitors from synthetic polyphenolic deoxybenzoins. Bioorg Med Chem 17: 4360-4366.

100. Rimbach G, De Pascual-Teresa S, Ewins BA, Matsugo S, Uchida Y, et al. (2003) Antioxidant and free radical scavenging activity of isoflavone metabolites. Xenobiotica 33: 913-925

101. Rüfer CE, Kulling SE (2006) Antioxidant activity of isoflavones and their major metabolites using different in vitro assays. J Agric Food Chem 54: 2926-2931.

102. Salti GI, Grewal S, Mehta RR, Das Gupta TK, Boddie AW Jr, et al. (2000) Genistein induces apoptosis and topoisomerase II-mediated DNA breakage in colon cancer cells. Eur J Cancer 36: 796-802.

103. Schmidt F, Knobbe CB, Frank B, Wolburg H, Weller M (2008) The topoisomerase II inhibitor, genistein, induces G2/M arrest and apoptosis in human malignant glioma cell lines. Oncol Rep 19: 1061-1066.

104. Azarova AM, Lin RK, Tsai YC, Liu LF, Lin CP, et al. (2010) Genistein induces topoisomerase Ilbeta- and proteasome-mediated DNA sequence rearrangements: Implications in infant leukemia. Biochem Biophys Res Commun 399: 66-71.

105. Ross JA, Potter JD, Robison LL (1994) Infant leukemia, topoisomerase II inhibitors, and the MLL gene. J Natl Cancer Inst 86: 1678-1680.

106. Strick R, Strissel PL, Borgers S, Smith SL, Rowley JD (2000) Dietary bioflavonoids induce cleavage in the MLL gene and may contribute to infant leukemia. Proc Natl Acad Sci U S A 97: 4790-4795.

107. Akiyama T, Ishida J, Nakagawa S, Ogawara H, Watanabe S, et al. (1987) Genistein, a specific inhibitor of tyrosine-specific protein kinases. J Biol Chem 262: 5592-5595

108. Salzman AL, Preiser JC, Setchell KD, Szabo C (1999) Isoflavone-mediated inhibition of tyrosine kinase: a novel antiinflammatory approach. J Med Food 2: $179-181$

109. Doerge DR, Chang HC (2002) Inactivation of thyroid peroxidase by soy isoflavones, in vitro and in vivo. J Chromatogr B Analyt Technol Biomed Life Sci 777: 269-279.

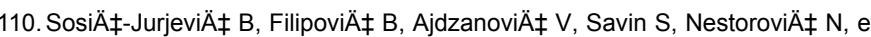
al. (2010) Suppressive effects of genistein and daidzein on pituitary-thyroid axis in orchidectomized middle-aged rats. Exp Biol Med (Maywood) 235: 590598.

111. Chorazy PA, Himelhoch S, Hopwood NJ, Greger NG, Postellon DC (1995) Persistent hypothyroidism in an infant receiving a soy formula: case report and review of the literature. Pediatrics 96: 148-150.

112. Messina M, Redmond G (2006) Effects of soy protein and soybean isoflavones on thyroid function in healthy adults and hypothyroid patients: a review of the relevant literature. Thyroid 16: 249-258.

113. Messina M (2010) A brief historical overview of the past two decades of soy and isoflavone research. J Nutr 140: 1350S-4S.

114. Polkowski K, Mazurek AP (2000) Biological properties of genistein. A review of in vitro and in vivo data. Acta Pol Pharm 57: 135-155.

115. Harper CE, Cook LM, Patel BB, Wang J, Eltoum IA, et al. (2009) Genistein and resveratrol, alone and in combination, suppress prostate cancer in SV-40 tag rats. Prostate 69: 1668-1682.

116. Pavese JM, Farmer RL, Bergan RC (2010) Inhibition of cancer cell invasion and metastasis by genistein. Cancer Metastasis Rev 29: 465-482.

117. Kyle E, Neckers L, Takimoto C, Curt G, Bergan R (1997) Genistein-induced apoptosis of prostate cancer cells is preceded by a specific decrease in focal adhesion kinase activity. Mol Pharmacol 51: 193-200.

118. Gu L, House SE, Prior RL, Fang N, Ronis MJ, et al. (2006) Metabolic phenotype of isoflavones differ among female rats, pigs, monkeys, and women. J Nutr 136: $1215-1221$.

119. Setchell KD, Brown NM, Zhao X, Lindley SL, Heubi JE, et al. (2011) Soy isoflavone phase II metabolism differs between rodents and humans: implications for the effect on breast cancer risk. Am J Clin Nutr 94: 1284-1294.

120. Travis RC, Allen NE, Appleby PN, Price A, Kaaks R, et al. (2012) Prediagnostic concentrations of plasma genistein and prostate cancer risk in 1,605 men with prostate cancer and 1,697 matched control participants in EPIC. Cancer Causes Control 23:1163-1171.

121.EFSA Panel on Dietetic Products, Nutrition and Allergies (NDA); Scientific Opinion on the substantiation of health claims related to soy isoflavones and protection of DNA, proteins and lipids from oxidative damage (ID 1286 4245), maintenance of normal blood LDL-cholesterol concentrations (ID 1135 , $1704 a, 3093 a)$, reduction of vasomotor symptoms associated with menopause (ID 1654, 1704b, 2140, 3093b, 3154, 3590), maintenance of normal skin tonicity (ID 1704a), contribution to normal hair growth (ID 1704a, 4254), "cardiovascular health" (ID 3587), treatment of prostate cancer (ID 3588), and "upper respiratory tract" (ID 3589) pursuant to Article 13(1) of Regulation (EC) No 1924/2006. (2011) EFSA Journal 9:2264-2308

122. [No authors listed] (1999) Food labeling: health claims; soy protein and coronary heart disease. Food and Drug Administration, HHS. Final rule. Fed Regist 64: 57700-57733.

123. Taku K, Umegaki K, Sato Y, Taki Y, Endoh K, et al. (2007) Soy isoflavones lower serum total and LDL cholesterol in humans: a meta-analysis of 11 randomized controlled trials. Am J Clin Nutr 85: 1148-1156.

124. Sacks FM, Lichtenstein A, Van Horn L, Harris W, Kris-Etherton P, et al. (2006) Soy protein, isoflavones, and cardiovascular health: an American Heart Association Science Advisory for professionals from the Nutrition Committee. Circulation 113: 1034-1044.

125. Namiki M, Akaza H, Lee SE, Song JM, Umbas R, et al. (2010) Prostate Cance Working Group report. Jpn J Clin Oncol 40 Suppl 1: i70-75.

126. EFSA Panel on Dietetic Products, Nutrition and Allergies (NDA) Scientific Opinion on the substantiation of a health claim related to soy protein and reduction of blood cholesterol concentrations pursuant to Article 14 of the Regulation (EC) No 1924/2006 (2010) EFSA Journal 8:1688. 